\title{
The Nia Project: Baseline report
}

\author{
Eunice N. Muthengi \\ Population Council \\ Emily Farris \\ Karen Austrian \\ Population Council
}

Follow this and additional works at: https://knowledgecommons.popcouncil.org/departments_sbsr-pgy

Part of the Demography, Population, and Ecology Commons, Family, Life Course, and Society Commons, International Public Health Commons, Maternal and Child Health Commons, and the Women's Health Commons How does access to this work benefit you? Let us know!

\section{Recommended Citation}

Muthengi, Eunice N., Emily Farris, and Karen Austrian. 2017. "The Nia Project: Baseline report." Nairobi: Population Council. 


\section{THE NIA PROJECT: BASELINE REPORT}

Eunice Muthengi

Emily Farris

Karen Austrian 


\section{porvuator COUNCIL \\ Ideas. Evidence. Impact.}

The Population Council confronts critical health and development issues-from stopping the spread of HIV to improving reproductive health and ensuring that young people lead full and productive lives. Through biomedical, social science, and public health research in 50 countries, we work with our partners to deliver solutions that lead to more effective policies, programs, and technologies that improve lives around the world. Established in 1952 and headquartered in New York, the Council is a nongovernmental, nonprofit organization governed by an international board of trustees.

Population Council

Avenue 5, 3rd Floor

Rose Avenue

P.O. Box 17643-00500

Nairobi, Kenya

Tel: +254 205134700

www.popcouncil.org

Suggested citation: Muthengi, Eunice, Emily Farris, and Karen Austrian. 2017. “The Nia Project: Baseline Report." Nairobi: Population Council. 


\section{Table of Contents}

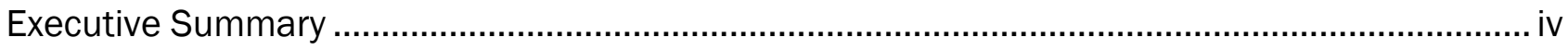

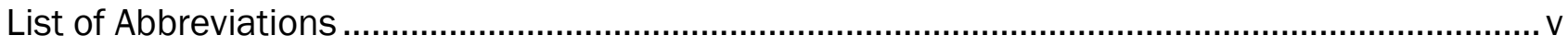

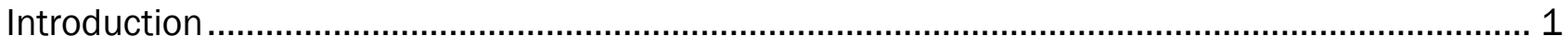

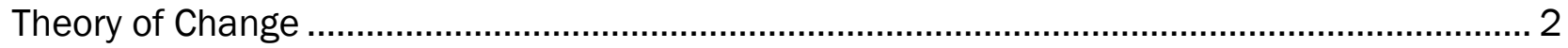

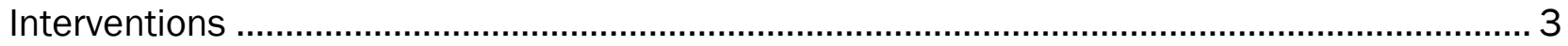

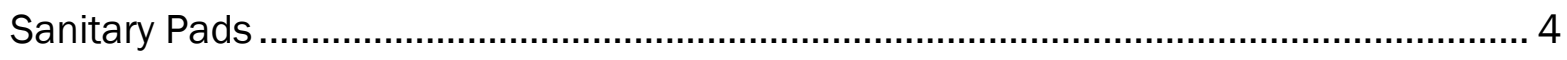

Reproductive Health Education .................................................................................. 4

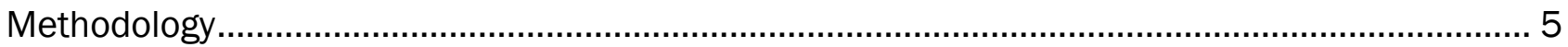

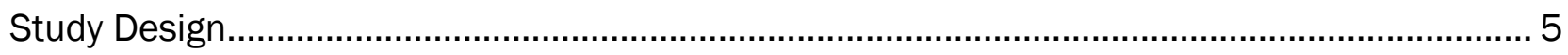

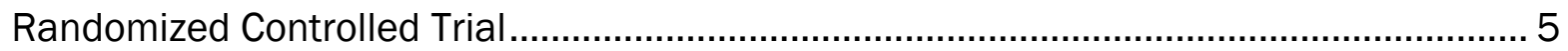

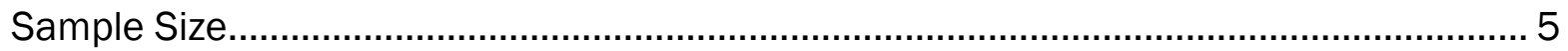

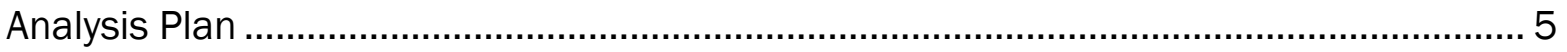

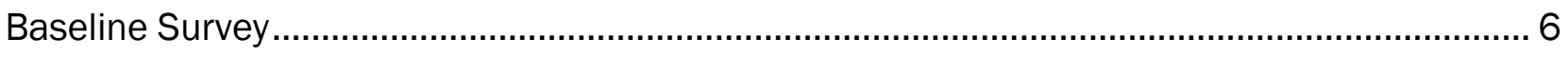

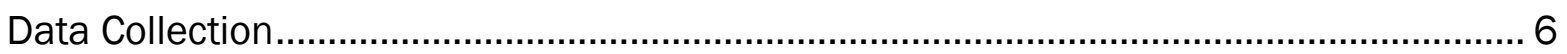

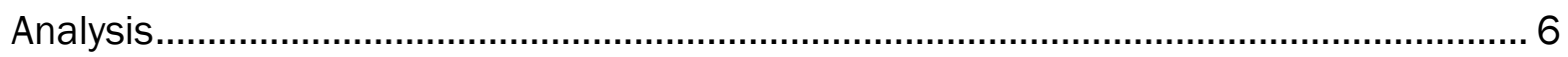

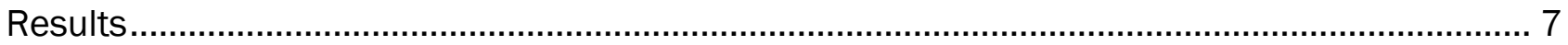

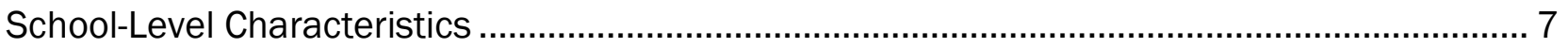

Socio-Demographic Characteristics of Adolescent Girls .......................................................... 8

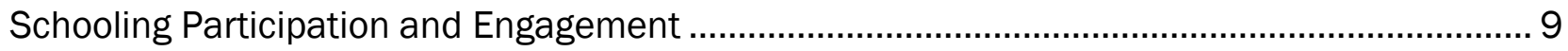

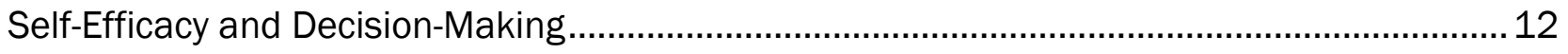

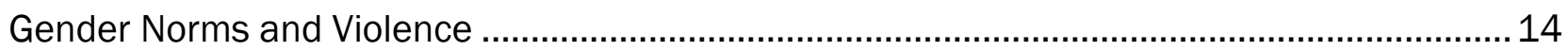

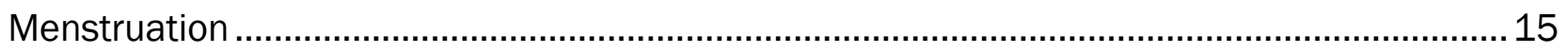

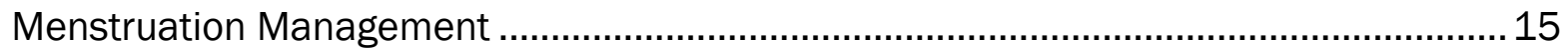

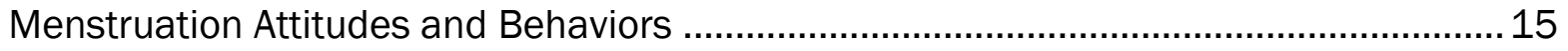

Reproductive Health and Sexual Behavior......................................................................... 17

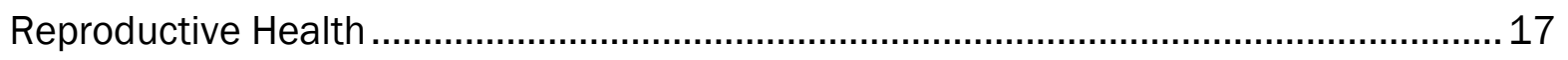

Marriage, Sexual Behavior, and Contraception ........................................................... 18

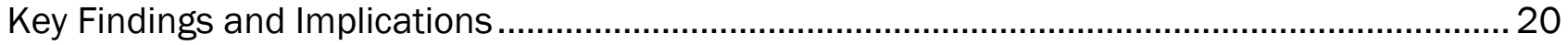

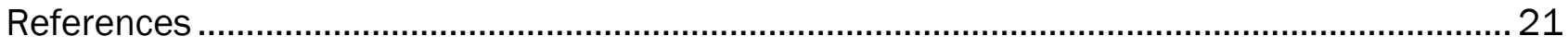

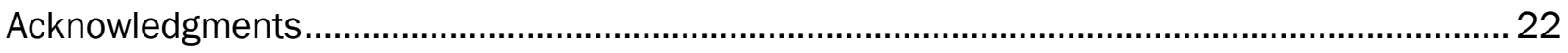




\section{Executive Summary}

The onset of puberty and menarche is a particularly vulnerable time for girls, a time when they begin to show interest in the opposite sex and also become exposed to a myriad of external pressures that include sexual coercion or harassment from boys and men, expectations to marry from their families, and the need to perform well in primary school in order to qualify for secondary school. These pressures are exacerbated by girls' lack of knowledge of their bodies, their rights, and the implications of their decisions, and by their inability to manage puberty and adolescence safely and comfortably with appropriate menstrual health and hygiene management (MHM) products.

Although several programs have previously been developed to address girls' MHM needs globally, few have been evaluated, and where evidence does exist the results have been mixed. Reviews of these studies indicate that there is a lack of rigorous studies demonstrating the effect of MHM on girls' general health and well-being.

In collaboration with ZanaAfrica, the Population Council is evaluating the Nia Project, a set of interventions for adolescent girls in Kilifi County, Kenya. Using a randomized controlled trial (RCT) research design, this evaluation analyzes the effect of distribution of Nia brand disposable sanitary pads and provision of reproductive health education (i.e., facilitated sessions and the Nia Teen magazine) on girls' education and reproductive health outcomes.

This report presents data from the baseline survey of the Nia Project, providing a multidimensional description of a sample of the girls who will be participating in the Nia Project and the schools they attend. The sample includes 3,489 girls from 140 schools in three rural Kilifi subcounties: Ganze, Kaloleni, and Magarini.

\section{KEY FINDINGS}

\section{Schooling}

Findings describe a cohort of Class 7 girls between 10 and 21 years of age, with high educational aspirations despite anticipated challenges, and substantial parental approval for education despite low levels of parental education. While most girls believe they are capable of doing well in school, a gap exists in some of the social and personal competencies that would empower them to complete secondary education and even continue to tertiary education.

\section{Menstruation}

Although girls have some access to disposable sanitary pads, a significant need for products to manage menstruation still exists, demonstrated by the large proportion of girls who report that they do not have enough pads, and those who did not receive pads in school in the previous term. In addition, girls shared feelings of shame and discomfort regarding their period that can potentially be improved by the group meetings and magazine.

\section{Reproductive Health}

Relatively low scores on the self-efficacy and decision-making scales, together with inequitable gender norms and a high justification for intimate-partner violence, suggest that substantial room for improvement exists through the Nia reproductive health education component to positively affect the girls. About a tenth were sexually experienced, and half of those reported their first sex as unwanted. Girls who had already initiated sex reported inconsistent condom use and very low use of other contraceptive methods, putting them at high risk of pregnancy and STIs, and increasing the likelihood of their stopping their education.

\section{CONCLUSION}

While gaps exist in girls' capabilities, particularly knowledge and attitudes related to menstruation and reproductive health, the Nia Project has the potential to bridge those gaps. The Project is one of the first RCTs to explore the role of sanitary pad distribution and reproductive health education - individually and in combinationto improve girls' educational and sexual and reproductive health (SRH) outcomes. The findings of this study will make a critical contribution to filling an evidence gap in the field of MHM, and in doing so will guide education and health policy in this area in Kenya and in the region. 


\section{List of Abbreviations}

ACAS

Audio Computer-Assisted Self Interviewing

CAPI Computer-Assisted Personal Interviewing

CSE Comprehensive Sexuality Education

FHE Facilitated Health Education

KCPE Kenya Certificate of Primary Education

KES Kenya Shillings

LSE Life Skills Education

MHM Menstrual Hygiene Management

NGO Nongovernmental Organization

ODK Open Data Kit

RCT Randomized Controlled Trial

$\mathrm{RH}$ Reproductive Health

SRHR Sexual and Reproductive Health and Rights 


\section{Introduction}

The onset of puberty and menarche is a particularly vulnerable time for girls, a time when they begin to show interest in the opposite sex and also become exposed to a myriad of external pressures, including sexual coercion or harassment from boys and men, expectations to marry from their families, and the need to perform well in primary school in order to qualify for secondary school (Sommer 2011). According to several qualitative studies in Africa, such pressures are exacerbated by girls' lack of knowledge of their bodies, their rights, and the implications of their decisions, and by their inability to manage puberty and adolescence safely and comfortably with appropriate menstrual health and hygiene management (MHM) products (Mukuru 2008; Sommer 2009, 2010; Crofts and Fisher 2012; Mason et al. 2013; Tegegne and Sisay 2014; Wilson, Reeve, and Pitt 2014).

Qualitative studies conducted in Kenya have identified several challenges girls face in managing their menstruation, including lack of access to menstrual products and lack of accurate information about menstruation. In a study conducted in Nyanza Province in Western Kenya, girls who participated in focus groups and in-depth interviews reported poverty as a main barrier to proper menstruation management. When families are unable to prioritize buying sanitary pads, girls resort to using cloths, mattress pieces, and other materials, but they describe these alternatives as ineffective in preventing leaking of blood onto their clothing (McMahon et al. 2011). In Siaya County, in Western Kenya, a qualitative study of young adolescent girls also highlighted the inadequacy of alternatives such as cloths, blankets, and mattress pieces, and the girls' preference for sanitary pads. Although the most common source of sanitary pads was mothers, some girls reported receiving money from boyfriends to buy pads, often with the expectation that they will have sex with them in return (Mason et al. 2013).

Both studies found that girls commonly had little or no knowledge of menstruation prior to menarche because traditional systems for passing on this knowledge were no longer functional and many mothers did not prepare their daughters for menstruation (McMahon et al. 2011; Mason et al. 2013). Data from focus group discussions in an informal settlement in Nairobi also showed that mothers' limited knowledge, embarrassment, and cultural taboos prevented them from providing their daughters with accurate information on reproductive health, including menstruation (Crichton, Ibisomi, and Gyimah 2012). Furthermore, teachers in Siaya most often stated that it was not their role to provide girls with information on menstruation (McMahon et al. 2011).

While several programs have previously been developed to address girls' MHM needs globally, few have been rigorously evaluated, and where evidence does exist the results have been mixed. A 2013 systematic review of the literature identified 14 studies that examined health outcomes such as reproductive tract infections (STIs) and 11 articles that examined psychosocial outcomes of menstrual hygiene (Sumpter and Torondel 2013). The authors concluded that while there is some evidence on the impact of MHM on psychosocial outcomes, the impact on health outcomes, specifically reproductive tract infections, is unclear. Furthermore, there is no quantitative evidence on the effects of MHM on reducing school absenteeism. They also noted the lack of rigorous studies showing the impact of MHM on girls' general health and well-being.

In 2016, Hennegan and Montgomery published a systematic review that identified eight studies that fulfilled their criteria: individual or cluster randomized controlled trials (RCTs) and nonrandomized controlled trials. The purpose of the review was to assess the risk of bias in these studies and synthesize the evidence on the effects of MHM interventions on educational and psychosocial outcomes for women and girls in low- and middle-income countries. The authors outlined two dominant types of MHM intervention approaches: hardware, or the provision of physical objects useful for MHM, such as menstrual cups or sanitary pads; and software, or the provision of human and social capital through education and nontangible benefits. The authors found considerable risk of bias in these studies, mainly selection bias, performance bias, attrition bias, and reporting bias. They were unable to synthesize most results because of differences in interventions and methods, and therefore concluded that while there are some indications of positive results, insufficient evidence exists for the effectiveness of MHM interventions.

Only one study identified in the review examined the effect of a combined software and hardware intervention on schooling attendance. The study was conducted in Ghana using a nonrandomized cluster-control trial design, with a sample of 120 girls between the ages of 12 and 18 (Montgomery et al. 2012). The three interventions implemented were: 1) provision of pads with puberty education, 2) puberty education alone, and 3) control group (no intervention). School attendance was measured using official school records, triangulated with researcher visits. At the end of the 5-month study period, study investigators observed statistically significant improvements in attendance for both treatment arms, by approximately 5 to 6 days per 65-day term. However, the main limitation of the study was the small sample size and nonrandomized design. Dolan and colleagues (2014) further reported a significant improvement over time in confidence regarding menstruation management in the study arm that 
included provision of pads. No statistically significant change in confidence (as measured by shame, selfconfidence, and insecurity) was observed in the education-only arm. However, as noted by Hennegan and Montgomery (2016), these findings should be interpreted with caution because confidence was not measured in the control group, and girls differed on this indicator across sites at baseline.

Because of the lack of clear evidence on the impact of MHM interventions on girls' education and health, ZanaAfrica received funding in 2015 from the Bill \& Melinda Gates Foundation to implement a holistic solution combining sanitary pads and reproductive health education, including multimedia health education resources. The package of interventions was branded as "The Nia Project," from the Swahili word nia, which means "purpose." ZanaAfrica is partnering with the Population Council to rigorously evaluate the Nia Project interventions among adolescent girls in Kilifi County, located in the coastal region of Kenya. Kilifi was identified as the study site based on a review of indicators related to education and reproductive health; for example, the low transition rate from primary to secondary school, recorded as $40 \%$ in 2010 , compared to the national rate of $72 \%$ (Ministry of Education Science and Technology 2012). In addition, Kilifi was ranked 36 out of 47 counties in regard to the Net Enrollment Rate for secondary school for boys and girls, which was only 26\% in 2014 (Ministry of Education Science and Technology 2014). According to the 2014 Kenya Demographic and Health Survey (Kenya National Bureau of Statistics and ICF International 2015), approximately 21.8\% of girls between the ages of 15 and 19 in Kilifi County had begun childbearing, compared to the national average of $18.1 \%$.

Using a randomized controlled trial (RCT) research design, this evaluation is one of the first to analyze the individual and combined contributions of sanitary pads and the provision of comprehensive reproductive health education on girls' education and reproductive health outcomes. The evidence provided will inform program investment and design, and will contribute to the literature on the effect of menstrual-health-based interventions on girls' agency, safety, and life outcomes.

The main objective of the research is to answer the following questions: 1) What is the effect of an MHM intervention combining software (reproductive health education) and hardware (sanitary pads) approaches on girls' well-being (social and personal competencies) and education, versus software or hardware alone? 2) What is the cost-effectiveness of the combined approach, as compared to either software or hardware approaches alone? The study was specifically designed to address key limitations of previous studies, which include small sample sizes, inability to determine causation, non-random assignment to study arms, and short follow-up periods.

This report describes the intervention and research design of the Nia Project and presents findings from the baseline survey conducted in 2017 before program implementation.

\section{THEORY OF CHANGE}

The Nia Project includes two intervention components: 1) provision of sanitary pads, and 2) reproductive health education, including MHM as an extracurricular program for girls enrolled in school. As shown in Figure 1, the project's theory of change hypothesizes that sanitary pad distribution will increase the use of pads to manage menstruation, which will lead to an increase in two short-term education indicators: 1) school attendance, and 2) participation/engagement in class. The bottom panel of the figure shows the hypothesized impact of the reproductive health education component on key short-term indicators of girls' social and personal competencies: 1) sexual and reproductive health and rights (SRHR) knowledge and attitudes, including menstrual health knowledge and attitudes, 2) gender norms, and 3) self-efficacy. This conceptual framework is based on Lloyd's (2013) typology of competencies (e.g., knowledge, skills, attitudes, and values) that basic education should incorporate in order to empower adolescent girls. According to this typology, social competencies include prosocial values (i.e., attitudes that are positive and/or beneficial for others and society), respect for human rights, and gender consciousness, whereas personal competencies include self-esteem, reproductive health knowledge, and both management and self-protective skills.

The combination of the two intervention components is hypothesized to synergistically increase the effect size for all outcomes, which could potentially affect longer-term outcomes, such as school retention, reduced unwanted sex, delayed pregnancy, and delayed first sex. While this study is powered to detect changes in the short-term indicators, additional analyses will be conducted to determine whether girls' observed short-term improvements are associated with longer-term impacts. 
FIGURE 1. NIA Project theory of change

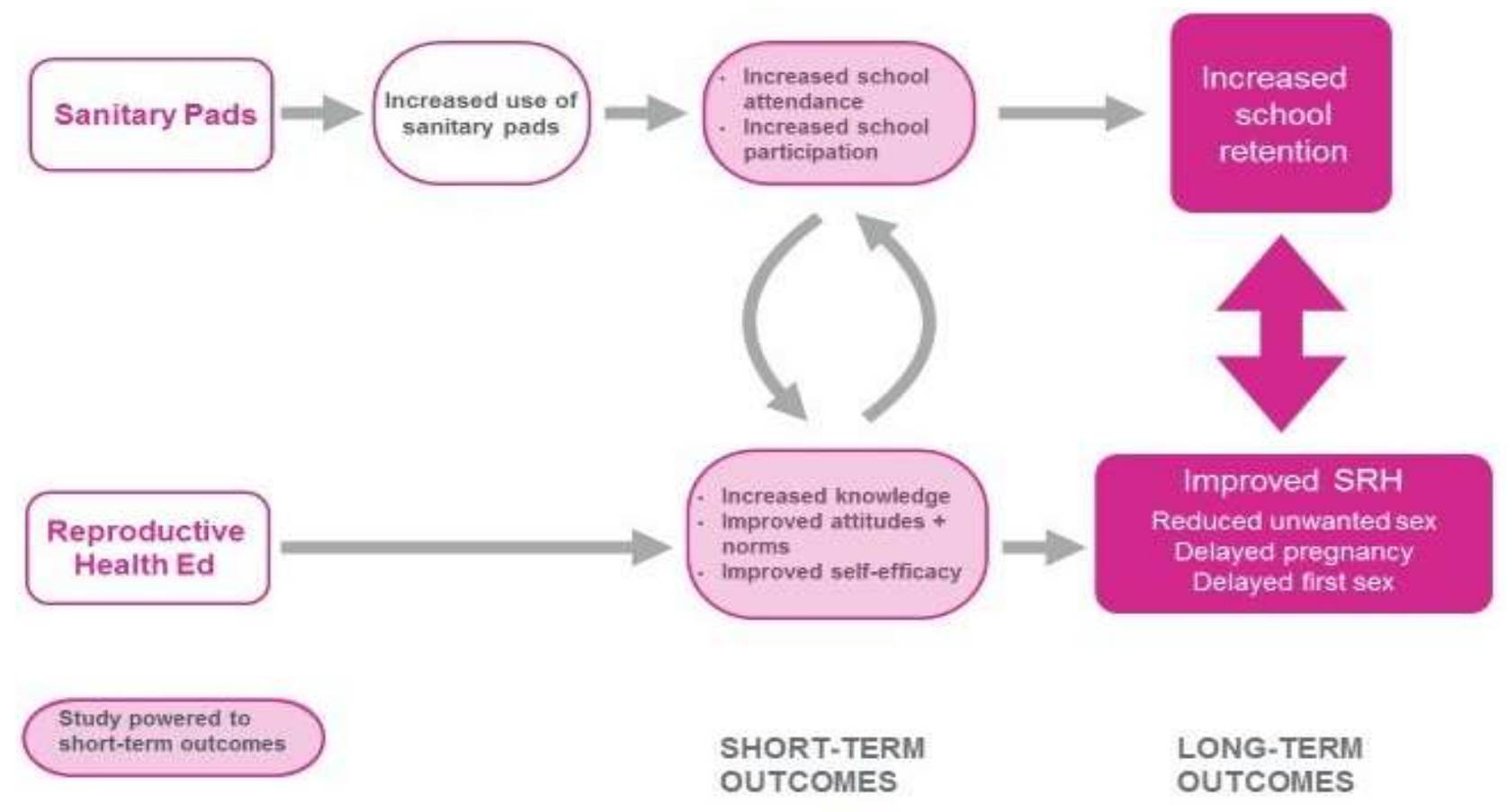

\section{INTERVENTIONS}

The Nia Project interventions are implemented by ZanaAfrica and Plan International, Kenya. Girls enrolled in Class 7 at the start of the 2017 school year are the beneficiaries, receiving interventions over a period of 5 school terms, from May 2017 to December 2018. Before program implementation, a total of 140 schools in three rural Kilifi subcounties (Ganze, Kaloleni, and Magarini) were stratified by subcounty and randomly assigned to one of the following four study arms:

1. Control group;

2. Sanitary pad distribution;

3. Reproductive health education; or

4. Sanitary pad distribution + reproductive health education.

FIGURE 2. NIA Project study design

\begin{tabular}{|c|c|c|c|}
\hline $\begin{array}{c}\text { Arm 1 } \\
35 \text { schools }\end{array}$ & $\begin{array}{c}\text { Arm 2 } \\
35 \text { schools }\end{array}$ & $\begin{array}{c}\text { Arm 3 } \\
35 \text { schools }\end{array}$ & $\begin{array}{c}\text { Arm 4 } \\
35 \text { schools }\end{array}$ \\
\hline $\begin{array}{c}\text { Control } \\
\text { (No intervention) }\end{array}$ & Sanitary Pads & $\begin{array}{c}\text { Reproductive } \\
\text { Health Ed }\end{array}$ & $\begin{array}{c}\text { Reproductive } \\
\text { Health Ed }\end{array}$ \\
\hline
\end{tabular}




\section{Sanitary Pads}

In 2011, the Kenyan government, through the Ministry of Education, Science and Technology, initiated the Schools' National Sanitary Towels program to increase girls' school attendance and participation. The program includes the provision of sanitary pads to school girls and the training of teachers on hygienic usage and disposal of pads (UNESCO Booklet 9-Puberty Education and MHM). However, results from a formative assessment conducted in Kilifi to inform the design of the Nia Project indicated that some schools receive inadequate supplies to meet the needs of all female students throughout the year.

For the Nia Project, each girl receives one packet of 10 ZanaAfrica Nia Teen brand disposable sanitary pads each month, for the entire project period. To avoid duplication, schools agreed to only distribute government-issued pads to girls who are not part of the Nia project, while ZanaAfrica distributes Nia pads to Class 7 girls. Lack of underwear was identified as a barrier to pad usage during the formative assessment. Therefore, project beneficiaries also receive two pairs of underwear at the start of the intervention, and an additional pair at the end of each subsequent term.

\section{Reproductive Health Education}

Kenyan primary education includes a National Life Skills Education curriculum, which focuses on communication, negotiation, and decision-making skills. The curriculum is not comprehensive and has been assessed as being weak in regard to topics such as: power in relationships, reproduction, sexuality and sexual behavior, HIV and sexually transmitted infections (STIs), contraceptives, and gender and human rights (Population Council 2012). Kenya's 2015 National Adolescent Sexual and Reproductive Health Policy provides the basis for the provision of age-appropriate comprehensive sexuality education (CSE) for in-school adolescents.

The Nia Project reproductive health education intervention is comprised of facilitated health education sessions (FHE) and a health magazine developed by ZanaAfrica. Both components are based on the UNESCO International Technical Guidance on Sexuality Education (Ecker, Kirby, and Gordon 2009) and designed to incorporate recent evidence on the importance of addressing gender and power in sexuality and HIV education programs (Haberland, 2015; Haberland and Rogow 2015). Nia Yetu, the curriculum for the FHE sessions, was developed by ZanaAfrica (2017) with many elements adapted from the Tuko Pamoja: Adolescent Reproductive Health and Life Skills Curriculum (Behague et al. 2006) developed by PATH and the Population Council as part of the Kenya Adolescent Reproductive Health Program (KARP). The 25-session curriculum is being delivered by trained facilitators during weekly girls-only health clubs in 2017 , and bi-monthly health clubs in 2018 , held during the time allocated for extracurricular activities in school.

ZanaAfrica's health magazine, Nia Teen, provides content that girls can refer to. It is designed to appeal to adolescent girls and conveys core reproductive health messages through storytelling using aspirational personal stories, a relatable comic-style story, and activities. Nia Teen magazine is distributed at the start of each term for the 5-term period. Each issue corresponds directly to the topics covered in each module of the Nia Yetu curriculum that term. 


\section{Methodology}

\section{STUDY DESIGN}

\section{Randomized Controlled Trial}

The design for the evaluation of the Nia Project is a longitudinal, cluster-randomized controlled trial consisting of a baseline survey with a cohort of Class 7 girls, a school quality survey, qualitative data collection, school attendance tracking, and an endline survey at the completion of the 18-month intervention period with the same cohort. The study involves 140 public primary schools (35 schools per arm) in three rural subcounties of Kilifi County in the Coastal area of Kenya.

The subcounties and schools were selected in collaboration with the Kilifi County Department of Education, Ministry of Education, Science and Technology. Within the three subcounties (Ganze, Kaloleni, and Magarini), all schools with 25 or more girls in Class 7 were eligible for the study. A total of 215 schools were mapped, and a 1,000-meter buffer was created around each school. For schools with overlapping boundaries, one school was randomly selected. This resulted in a list of 173 schools with at least 25 girls in Class 6 or in Class 7 in 2016 . A listing exercise was conducted to verify enrollment and school type in the first quarter of 2017. Based on this data, 25 schools were excluded because they did not meet the minimum criteria of 25 girls in Class 7 , and an additional seven were excluded because they were determined to be boarding schools. Subsequently, one school in Magarini was excluded after it was closed indefinitely by the Department of Education during baseline data collection. This resulted in 140 schools---44 in Magarini, 50 in Kaloleni, and 46 in Ganze.

In schools with 25 girls in Class 7, all girls were included in the research sample. In schools with a larger number of girls, 25 girls were randomly selected for the research sample and 5 additional girls were selected as alternates. All Class 7 girls, including those who were not in the research sample, are eligible to receive interventions. At the completion of data collection in each subcounty, stakeholder meetings were held and schools within that subcounty were randomly assigned to one of the four study arms through a public lottery.

\section{Sample Size}

The sample size was calculated based on power calculations to determine the number of clusters (i.e., schools) and the number of girls needed in each cluster to observe the desired change in the mean days of school missed, according to differences detected in previous studies conducted in Kenya and Ghana (Montgomery et al. 2012; Wilson et al. 2012). The estimate of the intra-cluster correlation (ICC) and the baseline estimates for childbearing and education were based on a previous menstrual health study conducted in Kenya by Wilson and colleagues (2012). With a sample size of 35 clusters per arm and 20 girls per cluster at endline (25 girls per cluster at baseline, assuming a loss of $20 \%$ by endline), the minimum detectable difference between study arms, with power of 0.80 and a significance level of 0.05 is:

- 1.18 mean days of school missed over a 4-week period, with an ICC of 0.173 and a standard deviation of 3.57 ; and

- a $13 \%$ increase in correct knowledge and attitudes on a reproductive health score from $75 \%$ to $85 \%$ in intervention arms with no change assumed in the control arm.

\section{Analysis Plan}

The program evaluation of the Nia Project will examine the effect of the average treatment across study arms while identifying the causal mechanisms driving that impact. Using intent-to-treat analysis, all girls in the original sample randomized to study arms will remain part of the study despite noncompliance, protocol deviations, withdrawal, or anything else that happens after randomization. Econometric estimation techniques such as fixed effects estimation will be applied to control for unobserved time invariant individual characteristics. The evaluation will compare the average increase in outcomes of girls in intervention arms to the average increase in outcomes of girls in the control arm. Additional hypotheses will be tested using difference in difference analysis to understand both causal mechanisms among girls who received the interventions and the potential effect of improvements in short-term indicators on longer-term outcomes. The rich dataset will provide an extensive list of variables that can be adjusted for directly in the analysis. The results will be triangulated using qualitative data. 
To examine balance across study arms following randomization, multinomial logistic regression models were estimated using each dataset to test for joint orthogonality for a selected list of indicators, comparing each treatment group with the control group. For the school quality dataset, the variables included were: school performance by gender, number of toilets, distribution of pads, and availability of pads in stock. The results showed that there were jointly no significant differences between study arms $(p=.60)$. For the girls' dataset, indicators included were: ever repeated a grade, age when starting school, self-efficacy scale, decision-making scale, gender-norms scale, reproductive health knowledge score, ever menstruated, justification of violence, experience of symptoms of reproductive health infections, and ever had sex. The results showed that there were jointly no significant differences between study arms $(p=0.14)$.

\section{BASELINE SURVEY}

\section{Data Collection}

In January and February 2017, prior to baseline data collection, a listing exercise was conducted in all project schools to identify all enrolled students in Class 7 and to collect basic contact information. Unique ID numbers were assigned to each student, random selection was conducted for schools with more than 25 girls in Class 7 , and the baseline sample list was generated. The baseline survey was conducted between February and May, 2017. Trained female interviewers led by a team leader visited villages associated with project schools to locate the households of selected girls. Before the surveys were conducted, informed consent was obtained from parents/guardians of the girls, and from the girls themselves. To the extent possible, interviews were conducted in a private area, with visual and auditory privacy, either at the home or the school.

The survey was conducted in either English or Swahili using Computer-Assisted Personal Interviewing (CAPI) on tablet computers and programmed with Open Data Kit (ODK) software. For sensitive questions regarding sexual behavior, the Audio Computer-Assisted Self Interviewing (ACASI) technique was used. With ACASI, respondents were provided with headphones through which they heard recordings of questions and response categories in their language of choice. They were then prompted to enter a response by touching a designated color for each response option.

Survey instruments were developed by study investigators and reviewed by the project's Research Advisory Committee. The girls' survey included topics such as: socio-demographic characteristics, education participation and engagement, social assets (i.e., friendship networks, self-esteem, trusting relationships with adults), selfefficacy, decision-making, financial literacy, menstruation, reproductive health knowledge, gender norms, sexual behavior, gender-based violence, literacy, mathematical assessments, and cognitive testing.

A school-quality survey was conducted with school administrators based on the Ministry of Education Science and Technology's Management Information System (MIS) questionnaire. The survey included information on teacherstudent ratios, utilities, performance on the national primary school exam, number of female teachers, the presence and type of latrines, observations of school facilities, and distribution of sanitary pads. These quality measures will be accounted for in future analysis as a mediating factor in the relationship between the intervention and schooling outcomes.

\section{Analysis}

Descriptive analysis was conducted using STATA to calculate frequencies, proportions, and means for key indicators by subcounty. Significance tests for categorical variables were conducted using the Pearson's ChiSquare. For continuous variables, linear regression models were estimated to test differences in means by subcounty, adjusting for clustering by school. Some indicators were measured using scales created from a list of related variables. Factor analysis was conducted and the results were used to include or exclude specific variables based on their factor loadings. The internal consistency or average correlation of items was measured using Chronbach's alpha. 


\section{Results}

The Nia Project baseline survey report describes characteristics of Class 7 girls in 140 primary schools in Kilifi County based on a sample of 3,489 respondents (Ganze=1,149 or 33\%; Kaloleni=1,247 or 36\%; Magarini=1,093 or 31\%). Descriptive data on school-level characteristics were based on responses provided by school administrators as part of the School Quality survey, and observational data collected by research assistants for 140 schools (Ganze=46; Kaloleni=50; Magarini=44). All results were presented for the entire sample, as well as stratified by subcounty. Differences between subcounties that were statistically significant at the level of $p<0.05$ are highlighted in the text. The Results section begins with a description of the school-level characteristics, followed by demographic characteristics of the sample of girls, and results for key study indicators grouped by topic: education participation and engagement, self-efficacy and decision-making, gender norms and violence, menstruation, and reproductive health and sexual behavior.

\section{SCHOOL-LEVEL CHARACTERISTICS}

All 140 schools included in the study were public, mixed-gender day schools. Only six of the schools reported providing partial boarding facilities. Table 1 shows selected school-level characteristics by subcounty. The mean Class 7 enrollment per school was 44 girls and 42 boys, with a significantly higher mean number of boys in Kaloleni (48) compared to Magarini (43) or Ganze (35). The mean score on performance in the Kenya Certificate of Primary Education (KCPE) examination conducted nationwide upon completion of primary school (Class 8 ) was 225 for girls, which was significantly lower than the mean score for boys (237). KCPE performance was significantly higher in Ganze subcounty for both girls and boys.

Information on school-level facilities included energy sources, water, and sanitation. Eighty-five percent of schools had electricity. Of those that did not, 29\% (6) had no light and 67\% (14) used a solar system. The schools' main drinking water sources were: tap (35\%), rain (21\%), water truck (15\%), borehole (7\%), or river (6\%). On average, schools had approximately seven functional toilets for all girls in the school, with a ratio of 52 girls per toilet. Ganze had a significantly smaller number of girls per toilet (38) than Kaloleni (59) and Magarini (57). Less than a quarter (32) of schools reported providing soap to their students, but according to observational data, only 12 schools actually provided soap for handwashing on the day of the survey.

Many schools reported charging various fees, including tuition (29\%), examination fees (94\%), activity fees (71\%), meals (31\%), and maintenance/construction (16\%). Of those that did charge fees, the average amounts charged for the first term of 2017 were: 191 Kenya Shillings (KES) for tuition, 165 KES for examination fees, and 123 KES for activity fees.

The majority of schools (85\%) distributed government-issued sanitary pads to girls. Of the 119 schools that did, more than half (69\%) reported providing pads monthly. However, based on observational data, only $57 \%$ of schools had sanitary pads in stock on the day of the survey. 


\begin{tabular}{|c|c|c|c|c|c|}
\hline & \multicolumn{4}{|c|}{ Subcounty } & \multirow[b]{2}{*}{$\begin{array}{c}P \\
\text { value }\end{array}$} \\
\hline & $\begin{array}{c}\text { Ganze } \\
(\mathrm{N}=46) \\
\text { Mean/\% }\end{array}$ & $\begin{array}{l}\begin{array}{c}\text { Kaloleni } \\
(\mathrm{N}=50)\end{array} \\
\text { Mean/\% }\end{array}$ & $\begin{array}{c}\text { Magarini } \\
(\mathrm{N}=44) \\
\text { Mean/\% }\end{array}$ & $\begin{array}{c}\text { Total } \\
(\mathrm{N}=140) \\
\text { Mean } \%\end{array}$ & \\
\hline \multicolumn{6}{|l|}{$\begin{array}{l}\text { Current enrollment } \\
\text { Girls, Class } 7 \text { [mean (SD)] }\end{array}$} \\
\hline $\begin{array}{c}{[\min =10 ; \max =140]} \\
\text { Boys, Class } 7 \text { [mean (SD)] }\end{array}$ & $40.9(12.9)$ & $48.7(25.5)$ & $43.5(20.4)$ & $44.5(20.6)$ & 0.159 \\
\hline $\begin{array}{l}\quad[\min =12 ; \max =130] \\
\text { Number of students per teacher } \\
{[\text { mean (SD)] }}\end{array}$ & $34.9(12.9)$ & $47.6(23.8)$ & $42.8(19.9)$ & $41.9(20.1)$ & 0.002 \\
\hline $\begin{array}{l}\qquad[\min =23 ; \max =141] \\
\text { Boys KCPE score [mean (SD)] }\end{array}$ & $42.9(12.7)$ & $54.0(16.2)$ & $40.4(14.4)$ & $46.1(15.7)$ & 0.249 \\
\hline $\begin{array}{l}{[\text { min=100; } \max =357]} \\
\text { Girls KCPE score [mean (SD)] }\end{array}$ & $266.6(35.4)$ & $222.7(39.2)$ & $222.5(39.5)$ & $237.1(43.1)$ & 0.000 \\
\hline $\begin{array}{l}\text { [min=100; } \max =345] \\
\text { School has electricity }\end{array}$ & $257.5(36.4)$ & $211.3(36.6)$ & $205.7(27.5)$ & $224.7(40.9)$ & 0.000 \\
\hline Yes & $82.6 \%$ & $94.0 \%$ & $77.3 \%$ & $85.0 \%$ & 0.066 \\
\hline No & $17.4 \%$ & $6.0 \%$ & $22.7 \%$ & $15.0 \%$ & \\
\hline $\begin{array}{l}\text { Girls' functional toilets [mean (SD)] } \\
\quad[\min =0 ; \text { max }=20 \text { ] } \\
\text { Number of girls per toilet [mean } \\
\text { (SD)] }\end{array}$ & $8.0(4.1)$ & $7.2(3.8)$ & $6.3(3.4)$ & $7.2(3.8)$ & 0.102 \\
\hline$[\min =11 ; \max =247]$ & $38.3(20.7)$ & $59.2(37.1)$ & $56.6(30.3)$ & $51.6(31.5)$ & 0.000 \\
\hline $\begin{array}{l}\text { Percent that provide soap } \\
\text { Percent that provided soap on date }\end{array}$ & $19.6 \%$ & $20.0 \%$ & $29.6 \%$ & $22.9 \%$ & 0.580 \\
\hline of interviewa & $15.2 \%$ & $6.0 \%$ & $4.6 \%$ & $8.6 \%$ & 0.141 \\
\hline Percent that provide pads & $89.1 \%$ & $74.0 \%$ & $93.2 \%$ & $85.0 \%$ & 0.030 \\
\hline $\begin{array}{l}\text { Percent with pads in stock on date } \\
\text { of interviewa }\end{array}$ & $54.4 \%$ & $52.0 \%$ & $65.9 \%$ & $57.1 \%$ & 0.356 \\
\hline
\end{tabular}

a Data based on observations recorded by research assistants on the day of the survey.

\section{SOCIO-DEMOGRAPHIC CHARACTERISTICS OF ADOLESCENT GIRLS}

Table 2 presents the socio-demographic characteristics of Class 7 girls who participated in the baseline survey. More than half of respondents were between the ages of 10 and 14 years (56\%) and $44 \%$ were between the ages of 15 and 21 years, with a mean of 14 years.

Approximately $84 \%$ of respondents were Christian and 13\% Muslim; Kaloleni had a significantly higher Muslim population (25\%) than Ganze (8\%) and Magarini (5\%). Only 3\% reported another religion or no religion.

About $82 \%$ of girls reported that both parents were still alive, while $13 \%$ had lost a father, $2 \%$ had lost a mother, and $1 \%$ had lost both parents. Only half of respondents (56\%) were reported as residing with both parents at the time of the survey. A quarter of girls (26\%) were residing with their mother only, 3\% with their father only, and $15 \%$ with neither parent. The education levels of respondents' parents were generally low, and significantly lower in Ganze as compared to the other two counties. Almost half of mothers (48\%) and $18 \%$ of fathers had never been to school, while only $3 \%$ of mothers and $13 \%$ of fathers completed secondary school. 


\begin{tabular}{|c|c|c|c|c|c|}
\hline & \multicolumn{4}{|c|}{ Subcounty } & \multirow[b]{3}{*}{$P$ value } \\
\hline & $\begin{array}{c}\text { Ganze } \\
(\mathrm{N}=1,149)\end{array}$ & $\begin{array}{c}\text { Kaloleni } \\
(\mathrm{N}=1,247)\end{array}$ & $\begin{array}{l}\text { Magarini } \\
(\mathrm{N}=1,093)\end{array}$ & $\begin{array}{c}\text { Total } \\
(\mathrm{N}=3,489)\end{array}$ & \\
\hline & Mean/\% & Mean/\% & Mean/\% & Mean/\% & \\
\hline $\begin{array}{l}\text { Age }[\text { mean (SD)] } \\
\quad[\min =10 ; \max =21] \\
\text { Age categories }\end{array}$ & $14.5(1.5)$ & $14.3(1.5)$ & $14.3(1.5)$ & $14.4(1.5)$ & 0.268 \\
\hline $10-14$ & $53.7 \%$ & $58.5 \%$ & $57.1 \%$ & $56.5 \%$ & 0.051 \\
\hline $15-21$ & $46.3 \%$ & $41.5 \%$ & $42.9 \%$ & $43.5 \%$ & \\
\hline \multicolumn{6}{|l|}{ Religion } \\
\hline Christian & $89.5 \%$ & $73.7 \%$ & $91.3 \%$ & $84.4 \%$ & 0.000 \\
\hline Islam & $8.1 \%$ & $24.5 \%$ & $5.1 \%$ & $13.0 \%$ & \\
\hline No religion/other & $2.4 \%$ & $1.8 \%$ & $3.6 \%$ & $2.6 \%$ & \\
\hline \multicolumn{6}{|l|}{ Parental survival status } \\
\hline Only mother alive & $14.8 \%$ & $12.0 \%$ & $12.5 \%$ & $13.1 \%$ & 0.696 \\
\hline Only father alive & $2.2 \%$ & $2.0 \%$ & $2.5 \%$ & $2.2 \%$ & \\
\hline Both parents alive & $80.0 \%$ & $83.1 \%$ & $82.1 \%$ & $81.8 \%$ & \\
\hline Both parents deceased & $1.5 \%$ & $1.4 \%$ & $1.5 \%$ & $1.4 \%$ & \\
\hline Do not know if father is alive & $1.6 \%$ & $1.6 \%$ & $1.5 \%$ & $1.6 \%$ & \\
\hline \multicolumn{6}{|l|}{ Participant lives with } \\
\hline Mother only & $27.2 \%$ & $25.7 \%$ & $24.3 \%$ & $25.8 \%$ & 0.163 \\
\hline Father only & $3.4 \%$ & $2.5 \%$ & $3.8 \%$ & $3.2 \%$ & \\
\hline Both parents & $54.9 \%$ & $58.4 \%$ & $55.8 \%$ & $56.4 \%$ & \\
\hline Neither parent & $14.5 \%$ & $13.5 \%$ & $16.1 \%$ & $14.6 \%$ & \\
\hline \multicolumn{6}{|l|}{ Level of education completed by mother } \\
\hline No education & $56.8 \%$ & $46.4 \%$ & $42.5 \%$ & $48.6 \%$ & 0.000 \\
\hline Nursey school, some primary & $21.7 \%$ & $23.1 \%$ & $31.5 \%$ & $25.3 \%$ & \\
\hline Complete primary, some secondary, vocational & $12.5 \%$ & $18.1 \%$ & $15.3 \%$ & $15.4 \%$ & \\
\hline $\begin{array}{l}\text { Complete secondary, post-secondary, } \\
\text { college/university }\end{array}$ & $2.3 \%$ & $4.7 \%$ & $2.7 \%$ & $3.3 \%$ & \\
\hline Do not know & $6.7 \%$ & $7.7 \%$ & $8.0 \%$ & $7.5 \%$ & \\
\hline \multicolumn{6}{|l|}{ Level of education completed by father } \\
\hline No education & $22.0 \%$ & $16.0 \%$ & $14.6 \%$ & $17.5 \%$ & 0.001 \\
\hline Nursey school, some primary & $23.6 \%$ & $23.4 \%$ & $23.4 \%$ & $23.5 \%$ & \\
\hline Complete primary, some secondary, vocational & $26.6 \%$ & $27.7 \%$ & $32.2 \%$ & $28.8 \%$ & \\
\hline $\begin{array}{l}\text { Complete secondary, post-secondary, } \\
\text { college/university }\end{array}$ & $11.3 \%$ & $14.1 \%$ & $13.1 \%$ & $12.9 \%$ & \\
\hline Do not know & $16.5 \%$ & $18.7 \%$ & $16.7 \%$ & $17.4 \%$ & \\
\hline
\end{tabular}

\section{SCHOOLING PARTICIPATION AND ENGAGEMENT}

Table 3 presents descriptive information on girls' participation and engagement in school. All respondents were enrolled in Class 7 in the 2017 school year. On average, girls reported starting school at age 7, with a minimum age of 4 years and a maximum age of 14 years, and this was significantly higher in Kaloleni ( 7.6 years). Due to the remoteness of areas within the study sites, girls were asked how long it usually takes them to get to school. The majority of girls $(96 \%)$ reported that they typically walk to school and the average travel time was 37 minutes ranging from zero minutes to 4 hours.

Repetition was common, particularly within the higher grades. Approximately two-thirds (66\%) of respondents had ever repeated a class, and this was significantly higher in Ganze (74\%) as compared to Kaloleni (58\%) and Magarini (67\%). Among those who had repeated, $71 \%$ repeated only one class, $25 \%$ repeated two classes, and $4 \%$ repeated three or four classes. About $39 \%$ of girls had repeated Class 7 , a quarter (25\%) had repeated Class 6 , and one-fifth $(20 \%)$ had repeated Class 4 or Class 5.

Girls were asked to spontaneously state the multiple reasons why they missed school during the previous school term. About $41 \%$ of girls reported missing school for any reason during the previous term. Among those, the most commonly reported reason for absence was illness (73\%), lack of school fees (11\%), other (6\%), bereavement 
(4\%), and menstruation (3\%). The "other" category mainly consisted of responses related to lack of food, water, and school uniforms. Within one school term, among girls who reported each reason, the average number of days missed was 3.7 days due to illness, 3.9 days due to lack of school fees, and 3.4 days due to menstruation. Among girls who mentioned menstruation, the specific reasons mentioned most frequently were the lack of materials to manage their period, and experiencing pain, cramps, or headaches.

Girls' perceptions regarding schooling indicate high levels of parental approval (96\% mothers; $85 \%$ fathers). Almost all girls indicated access to female teachers who encourage them to do well in school (91\%) and nearly all believe in the importance of secondary school education for girls (98\%). However, about two out of five girls (39\%) indicated that they sometimes have a high workload at home that prevents them from completing homework. Generally, girls had high educational aspirations. When asked to identify the highest level of school they would like to complete, $80 \%$ of girls aspired to complete college/university, and $19 \%$ aspired to complete secondary school. Of those who aspired to complete secondary school or higher, only $14 \%$ reported that they did not actually expect to be able to complete secondary school. The main barrier cited by these girls was the inability to pay school fees (94\%).

The survey included 10 questions from a school participation and competence scale from previous studies. However, in this sample, the scale had very low reliability with a Chronbach's alpha of 0.47 . Therefore, for school engagement, Table 3 includes only the five new items that were created specifically for this survey. Almost all girls reported that they are always able to complete their schoolwork (93\%). However, this could be overreported considering that, as described above, two out of five girls have a high workload at home that prevents them from completing homework. The majority of girls (95\%) agreed that they feel comfortable participating in class and they believe they are capable of doing well in school (97\%). About a third of girls (35\%), however, did not feel confident answering questions in class and $18 \%$ reported that they find it difficult to pay attention in class. 


\section{Subcounty}

\begin{tabular}{|c|c|c|c|c|c|c|}
\hline & $\begin{array}{c}\text { Ganze } \\
(\mathrm{N}=1,149)\end{array}$ & $\begin{array}{l}\text { Kaloleni } \\
(\mathrm{N}=1,247)\end{array}$ & $\begin{array}{l}\text { Magarini } \\
(\mathrm{N}=1,093)\end{array}$ & $\begin{array}{c}\text { Total } \\
(\mathrm{N}=3,489)\end{array}$ & \multirow{2}{*}{$(\mathrm{N})$} & \multirow[b]{2}{*}{$P$ value } \\
\hline & Mean/\% & Mean/\% & Mean/\% & Mean/\% & & \\
\hline $\begin{array}{l}\text { Age at start of Class } 1 \text { [mean } \\
\text { (SD)] } \\
\quad[\min =4 ; \max =14]\end{array}$ & $7.3(1.5)$ & $7.6(1.5)$ & $7.3(1.6)$ & $7.4(1.5)$ & & 0.011 \\
\hline $\begin{array}{l}\text { Travel time to school in minutes } \\
{[\text { mean (SD)] }} \\
{[\text { min=0; } \max =240]}\end{array}$ & $39.9(32.4)$ & $34.7(26.0)$ & $36.2(31.2)$ & $36.9(29.9)$ & & 0.057 \\
\hline $\begin{array}{l}\text { Highest level of school you would } \\
\text { like to complete: }\end{array}$ & & & & & & 0.019 \\
\hline Primary school & $0.09 \%$ & $0.16 \%$ & $27.00 \%$ & $17.00 \%$ & & \\
\hline Pre-secondary vocational & $0.17 \%$ & $0.00 \%$ & $0.55 \%$ & $0.23 \%$ & & \\
\hline Secondary school & $20.19 \%$ & $20.13 \%$ & $16.47 \%$ & $19.00 \%$ & & \\
\hline Post-secondary vocational & $0.61 \%$ & $0.72 \%$ & $1.28 \%$ & $0.86 \%$ & & \\
\hline College/university & $78.94 \%$ & $78.99 \%$ & $81.43 \%$ & $79.74 \%$ & & \\
\hline $\begin{array}{l}\text { Percent that ever repeated a } \\
\text { class } \\
\text { Class(es) repeated: }\end{array}$ & $73.5 \%$ & $57.8 \%$ & $67.3 \%$ & $66.0 \%$ & 2,301 & 0.000 \\
\hline Class 1 & $7.5 \%$ & $10.5 \%$ & $11.4 \%$ & $9.7 \%$ & & 0.020 \\
\hline Class 2 & $6.5 \%$ & $9.4 \%$ & $10.6 \%$ & $8.7 \%$ & & 0.012 \\
\hline Class 3 & $10.1 \%$ & $9.6 \%$ & $12.8 \%$ & $10.8 \%$ & & 0.102 \\
\hline Class 4 & $25.2 \%$ & $12.6 \%$ & $21.7 \%$ & $20.1 \%$ & & 0.000 \\
\hline Class 5 & $25.5 \%$ & $14.6 \%$ & $19.7 \%$ & $20.2 \%$ & & 0.000 \\
\hline Class 6 & $24.9 \%$ & $28.2 \%$ & $21.6 \%$ & $24.9 \%$ & & 0.015 \\
\hline Class 7 & $40.4 \%$ & $40.4 \%$ & $34.4 \%$ & $38.5 \%$ & & 0.022 \\
\hline $\begin{array}{l}\text { Most common reasons for } \\
\text { missing school in previous term }\end{array}$ & & & & & 1,418 & \\
\hline Sick/ill & $76.6 \%$ & $77.5 \%$ & $65.5 \%$ & $73.2 \%$ & & 0.000 \\
\hline Menstruation & $2.6 \%$ & $3.1 \%$ & $3.8 \%$ & $3.2 \%$ & & \\
\hline Bereavement/funeral & $2.6 \%$ & $6.2 \%$ & $3.6 \%$ & $4.2 \%$ & & \\
\hline School fees not paid & $9.1 \%$ & $5.8 \%$ & $17.0 \%$ & $10.6 \%$ & & \\
\hline Other & $6.9 \%$ & $4.8 \%$ & $6.4 \%$ & $6.0 \%$ & & \\
\hline \multicolumn{7}{|l|}{$\begin{array}{l}\text { Percent that agree with the } \\
\text { following: }\end{array}$} \\
\hline $\begin{array}{l}\text { It is as important for girls to } \\
\text { complete secondary school as it } \\
\text { is for boys }\end{array}$ & $98.5 \%$ & $98.2 \%$ & $98.1 \%$ & $98.3 \%$ & & 0.715 \\
\hline $\begin{array}{l}\text { There is a female teacher who } \\
\text { encourages you to do well in } \\
\text { school }\end{array}$ & $90.3 \%$ & $89.0 \%$ & $93.6 \%$ & $90.9 \%$ & & 0.000 \\
\hline $\begin{array}{l}\text { Your father approves of you } \\
\text { going to school }\end{array}$ & $83.7 \%$ & $85.4 \%$ & $86.1 \%$ & $85.1 \%$ & & 0.001 \\
\hline $\begin{array}{l}\text { Your mother approves of you } \\
\text { going to school }\end{array}$ & $96.6 \%$ & $96.3 \%$ & $96.2 \%$ & $96.4 \%$ & & 0.709 \\
\hline $\begin{array}{l}\text { At times, you have so much } \\
\text { work at home you cannot } \\
\text { complete homework }\end{array}$ & $38.4 \%$ & $37.1 \%$ & $41.9 \%$ & $39.0 \%$ & & 0.001 \\
\hline \multicolumn{7}{|l|}{ School engagement } \\
\hline $\begin{array}{l}\text { Percent that agree with the } \\
\text { following: } \\
\text { You feel comfortable }\end{array}$ & & & & & & \\
\hline $\begin{array}{l}\text { participating in class } \\
\text { You do not feel confident }\end{array}$ & $95.5 \%$ & $95.3 \%$ & $94.5 \%$ & $95.1 \%$ & & 0.541 \\
\hline $\begin{array}{l}\text { answering questions in class } \\
\text { It is difficult for you to pay }\end{array}$ & $33.4 \%$ & $36.9 \%$ & $32.9 \%$ & $34.5 \%$ & & 0.179 \\
\hline $\begin{array}{l}\text { attention in class } \\
\text { You always complete your }\end{array}$ & $15.8 \%$ & $19.1 \%$ & $18.9 \%$ & $17.9 \%$ & & 0.021 \\
\hline $\begin{array}{l}\text { schoolwork } \\
\text { You believe you are capable of }\end{array}$ & $94.1 \%$ & $93.5 \%$ & $91.8 \%$ & $93.2 \%$ & & 0.093 \\
\hline doing well in school & $97.6 \%$ & $96.9 \%$ & $96.9 \%$ & $97.1 \%$ & & 0.442 \\
\hline
\end{tabular}




\section{SELF-EFFICACY AND DECISION-MAKING}

Table 4 shows the distribution for the self-efficacy and decision-making scales. Respondents were asked whether they agree or disagree with 10 statements from the General Self-Efficacy Scale (Schwarzer and Jerusalem 2010). Ranging from 0 to 10, the average score on the scale was 5.3, showing a generally low level of self-efficacy. The statement on which respondents demonstrated the highest and lowest levels of self-efficacy were: "If you are in trouble, you can usually think of a solution" (77\%), and "If someone is against you, you can still find ways to get what you want" (32\%), respectively.

The 12 items included in the decision-making scale are also shown in Table 5. The average score on the scale was 6.3 , reflecting the number of statements for which respondents endorsed as "often" applicable to them, or decisions that they "often" are able to make on their own without an adult. Alternative responses included: "sometimes," "never/rarely," or "don't know." The statement on which respondents demonstrated the highest level of decision-making ability was: how often the respondent can make decisions about "who you can have as friends" without an adult (73\%). 


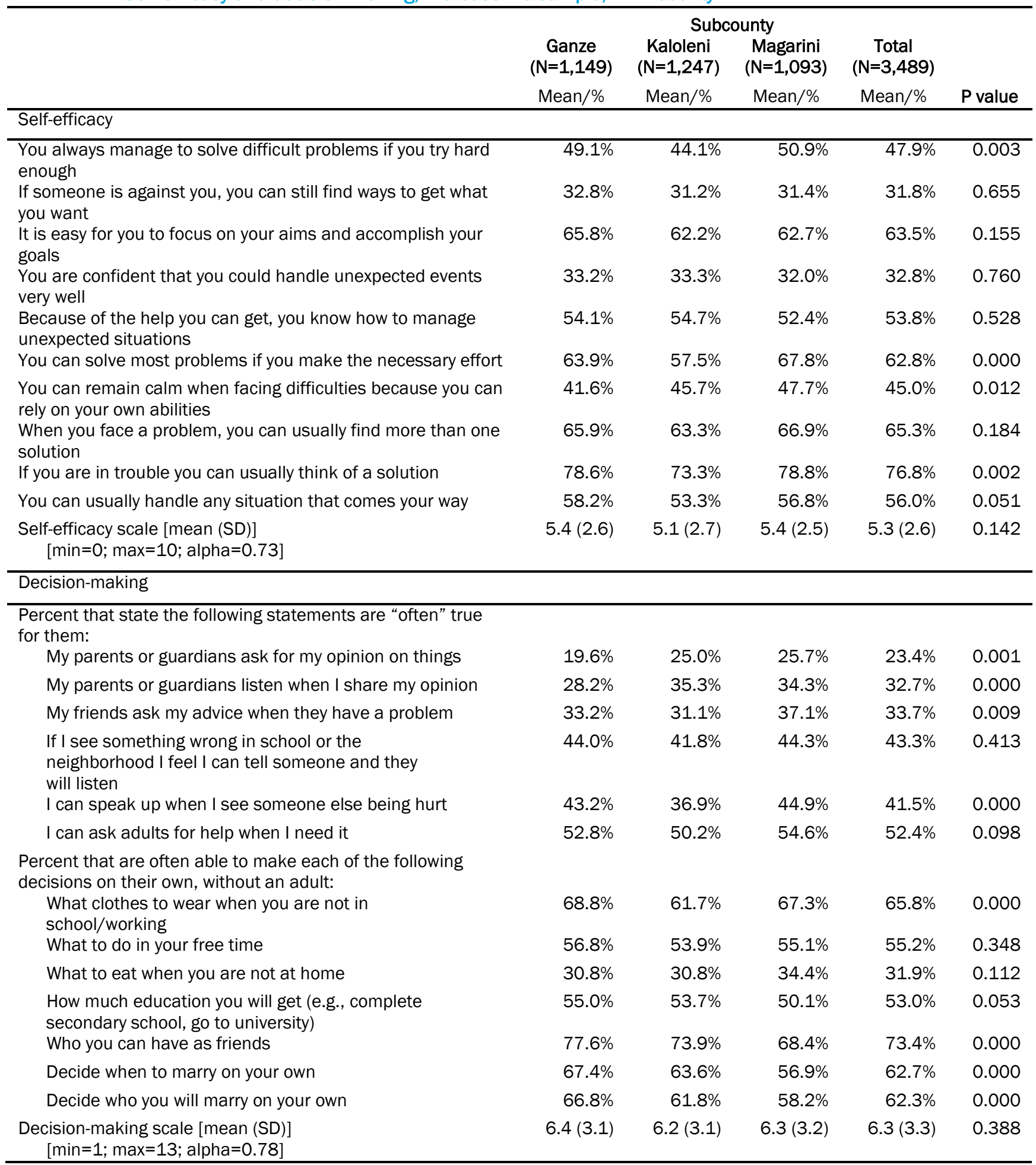




\section{GENDER NORMS AND VIOLENCE}

Results regarding gender norms and violence are presented in Table 5. Based on factor analysis, four items were selected from a list of statements to create a gender-norm scale with scores ranging from 0 to 4 . The average score was 1.8, indicating that girls generally held positive norms regarding two of the four statements. On average, girls in Ganze had a significantly higher score than girls in other subcounties. Only one out of four girls (26\%) agreed with the statement "Girls should be able to move as freely as boys." The statement with the highest level of agreement was "Boys and girls should be equally responsible for household chores" (59\%).

Attitudes regarding gender-based violence were assessed by asking girls whether they believed it is justifiable for a husband to beat his wife for several reasons. Seventy-two percent of girls agreed that wife-beating is justified in at least one instance, with higher reporting in Magarini (76\%) as compared to Ganze (70\%) and Kaloleni (69\%) subcounties. Older girls (ages 15 to 21 ) were significantly more likely to justify wife-beating as compared to younger girls. Overall, the proportion of girls endorsing each reason is as follows: if she goes out without telling him $(52 \%)$, if she neglects the children (56\%), if she argues with him (49\%), if she refuses to have sex with him (25\%), and if she burns the food (21\%).

About $23 \%$ of respondents had experienced violence perpetrated by a male in the previous year. Respondents from Magarini were significantly more likely to report violence (29\%) than respondents in Ganze (21\%) or Kaloleni (20\%). In Kaloleni only, older girls were significantly more likely to report violence than younger girls (24\% ages 15 to $21 ; 18 \%$ ages 10 to 14$)$. Girls were more likely to report experiencing physical violence (14\%) and emotional violence $(12 \%)$, as compared to $6 \%$ of respondents reporting sexual violence. The following are the types of males who were reported as the perpetrators of violence: student (37\%), neighbor (25\%), teacher (20\%), relative (23\%), stranger (10\%), parent/guardian (6\%), husband/boyfriend/fiancé (5\%), or friend (4\%). Only about half (58\%) of girls who experienced violence stated that they ever tried to seek help to stop this/these person(s) from doing this to them again. Of those who did, girls mainly sought help from their own families $(66 \%)$, community leaders/local administration (38\%), friends (13\%), and neighbors (5\%).

TABLE 5 Gender norms and violence, Nia baseline sample, Kilifi County

\begin{tabular}{|c|c|c|c|c|c|}
\hline \multirow[b]{3}{*}{ Gender norms } & \multicolumn{4}{|c|}{ Subcounty } & \multirow[b]{3}{*}{$P$ value } \\
\hline & \multirow{2}{*}{$\begin{array}{c}\text { Ganze } \\
(\mathrm{N}=1,149) \\
\text { Mean/\% }\end{array}$} & \multirow{2}{*}{$\begin{array}{c}\text { Kaloleni } \\
(\mathrm{N}=1,247) \\
\text { Mean/\% }\end{array}$} & \multirow{2}{*}{$\begin{array}{c}\text { Magarini } \\
(\mathrm{N}=1,093) \\
\text { Mean/\% }\end{array}$} & \multirow{2}{*}{$\begin{array}{c}\text { Total } \\
(\mathrm{N}=3,489) \\
\text { Mean/\% }\end{array}$} & \\
\hline & & & & & \\
\hline Girls should be as independent as boys & $45.9 \%$ & $42.5 \%$ & $35.0 \%$ & $41.3 \%$ & 0.000 \\
\hline $\begin{array}{l}\text { Girls should have the same opportunities as } \\
\text { boys }\end{array}$ & $57.1 \%$ & $47.0 \%$ & $47.5 \%$ & $50.5 \%$ & 0.000 \\
\hline Girls should be able to move as freely as boys & $31.5 \%$ & $26.7 \%$ & $18.7 \%$ & $25.8 \%$ & 0.000 \\
\hline $\begin{array}{l}\text { Boys and girls should be equally responsible } \\
\text { for household chores }\end{array}$ & $63.2 \%$ & $58.2 \%$ & $54.4 \%$ & $58.6 \%$ & 0.000 \\
\hline $\begin{array}{r}\text { Gender norms scale [mean (SD)] } \\
{[\min =1 ; \max =4 ; \text { alpha }=0.65]}\end{array}$ & $2.0(1.4)$ & $1.7(1.4)$ & $1.6(1.3)$ & $1.8(1.4)$ & 0.000 \\
\hline \multicolumn{6}{|l|}{ Gender-based violence } \\
\hline \multicolumn{6}{|l|}{ Percent that agree wife-beating is justified if: } \\
\hline She goes out without telling him & $50.2 \%$ & $50.0 \%$ & $55.4 \%$ & $51.8 \%$ & 0.013 \\
\hline She neglects the children & $53.8 \%$ & $52.5 \%$ & $61.8 \%$ & $55.8 \%$ & 0.000 \\
\hline She argues with him & $47.0 \%$ & $48.1 \%$ & $51.4 \%$ & $48.8 \%$ & 0.094 \\
\hline She refuses to have sex with him & $26.0 \%$ & $20.7 \%$ & $28.0 \%$ & $24.7 \%$ & 0.000 \\
\hline She burns the food & $21.3 \%$ & $20.1 \%$ & $22.1 \%$ & $21.1 \%$ & 0.514 \\
\hline $\begin{array}{l}\text { Percent that agree wife-beating is justified for } \\
\text { at least one reason }\end{array}$ & $70.1 \%$ & $69.0 \%$ & $76.0 \%$ & $71.5 \%$ & 0.000 \\
\hline Experienced violence in the previous year & $21.3 \%$ & $20.5 \%$ & $28.6 \%$ & $23.3 \%$ & 0.000 \\
\hline Emotional violence & $9.8 \%$ & $9.0 \%$ & $16.9 \%$ & $11.8 \%$ & 0.000 \\
\hline Physical violence & $14.3 \%$ & $11.7 \%$ & $17.8 \%$ & $14.5 \%$ & 0.000 \\
\hline Sexual violence & $4.5 \%$ & $5.0 \%$ & $7.9 \%$ & $5.7 \%$ & 0.001 \\
\hline
\end{tabular}




\section{MENSTRUATION}

\section{Menstruation Management}

Table 6 presents respondents' experiences, behaviors, and attitudes regarding menstruation. The majority of respondents (80\%) had begun menstruating, with a significantly higher proportion of girls in Ganze (84\%) as compared to Kaloleni $(77 \%)$ and Magarini ( $81 \%)$. The average age of first menstruation was 13.4 years, ranging from 9 to 17, and this was significantly lower in Ganze (13.2 years). Respondents were asked from whom they first received information on menstruation, and they could select multiple responses. The primary sources of information were: teachers (39\%), friends (38\%), mothers (33\%) and sisters (31\%), and other relatives (15\%). Most girls $(80 \%)$ stated that they told someone when they first started menstruating (multiple responses possible), mainly: mothers (65\%), sisters (27\%), and friends (17\%).

Almost all girls reported disposable sanitary pads as the main method they use to manage menstruation at home (94\%) and at school (97\%). Some other methods used were old pieces of cloth (20\%), new pieces of cloth (4\%), and cotton wool (3\%). Among those who reported using any other method apart from the main method, $98 \%$ identified disposable sanitary pads as their preferred method for managing menstruation. About $38 \%$ reported ever having blood leak onto their bodies or clothes while at school, with the majority stating that it happened rarely $(59 \%)$, or sometimes $(36 \%)$. When asked where they get pads and other materials (multiple responses possible), the most common responses were: "school" (71\%), "I buy them" (55\%), "given by mother" (22\%), "from my home" (7\%), "given by other relative" (5\%), and "from friends" (4\%). Girls in Kaloleni were significantly more likely to report buying the materials (60\%) as compared to girls from Magarini (48\%). For girls who buy pads themselves, the most common sources of money (multiple responses possible) for these purchases were: parents (89\%), other family members (11\%), boyfriends (1\%), and their own savings (7\%).

Most girls ( $81 \%$ school; $82 \%$ home) reported that they are always able to change their pads or other materials when needed, and among those, approximately three-quarters ( $73 \%$ school; $76 \%$ home) said they are often able to do so in private. The proportion of girls who are always able to change their pads or other materials was significantly higher for girls in Kaloleni ( $87 \%$ school; $90 \%$ home) as compared to girls in Magarini ( $71 \%$ school, $75 \%$ home). Almost all girls (98\%) dispose of their pads or other materials inside latrines while at school. At home, only half of girls dispose of pads inside latrines $(52 \%)$, with a significantly higher proportion for Kaloleni girls (76\%) as compared to girls in Ganze (43\%) and Magarini (35\%). Other disposal places while at home include dropping them in the field (25\% Ganze; 11\% Kaloleni; 22\% Magarini), burning them in the field (4\% Ganze; $2 \%$ Kaloleni; $8 \%$ Magarini), and "other" (27\% Ganze; 10\% Kaloleni; 35\% Magarini), which included responses related to burning them in a bush, throwing them in a bush, or washing the pieces of cloth.

It was clear that there is still a gap in access to materials to manage menstruation. Among menstruating girls, only one-fifth (21\%) said "yes" when asked whether they feel they have enough pads to manage their periods comfortably. Only half (54\%) reported receiving pads at school during the previous term, and this proportion was significantly higher in Ganze (60\%) and Magarini (60\%) as compared to Kaloleni $(42 \%)$. The majority of these girls received pads once or twice during the three-month term followed by one holiday month, with most receiving one or two packets at a time.

\section{Menstruation Attitudes and Behaviors}

Respondents were asked whether they agreed or disagreed with statements regarding their feelings surrounding menstruation and their bodies. Almost all girls (96\%) agreed that menstruation is a normal process for girls, but many $(89 \%)$ agreed it is important that they keep their period secret from anyone. Girls also expressed feelings of shame and discomfort regarding periods. Forty-three percent agreed that they feel ashamed of their body when having their period, and this proportion was significantly higher in Magarini (35\% Ganze; 44\% Kaloleni; and 51\% Magarini). About two-thirds (67\%) agreed that they feel uncomfortable in their bodies when having their period, and $17 \%$ of girls agreed that a girl is unclean when she is having her period. Alternatively, about $70 \%$ of girls agreed that they are proud that they have their periods, and $73 \%$ agreed they can easily concentrate in class while having their periods.

About a third of girls reported that there are activities they are forbidden to engage in (28\% Ganze; $31 \%$ Kaloleni; $37 \%$ Magarini) and activities that they choose not to engage in during their periods (32\% Ganze; 34\% Kaloleni; $39 \%$ Magarini). These proportions were significantly higher for girls in Magarini subcounty. The main activities were: interacting with men/boys ( $27 \%$ forbidden; $18 \%$ choose not to), cooking for the family ( $19 \%$ forbidden; $21 \%$ choose not to), and playing games/sports (10\% forbidden; $32 \%$ choose not to). 


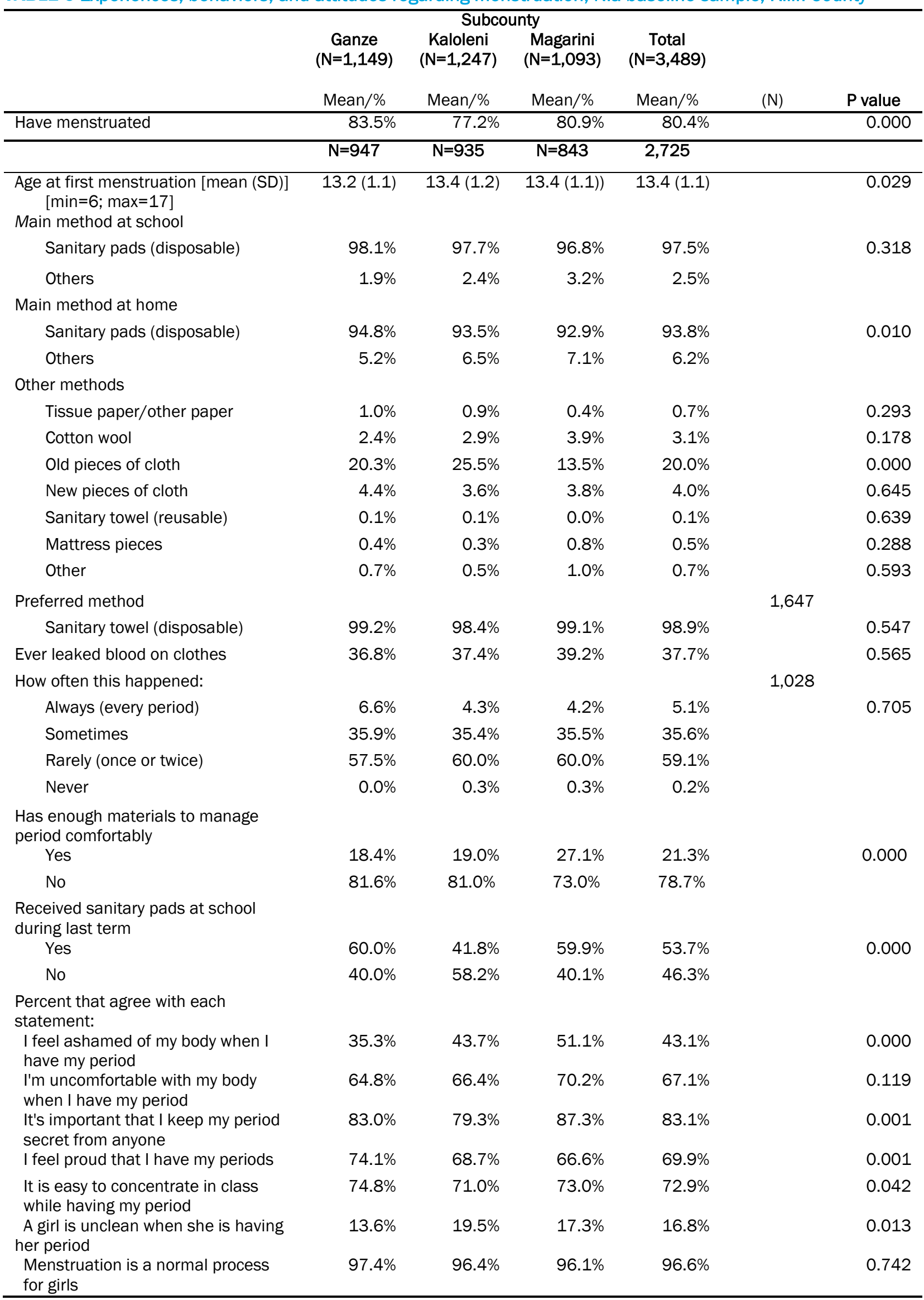




\section{REPRODUCTIVE HEALTH AND SEXUAL BEHAVIOR}

\section{Reproductive Health}

Descriptive information on reproductive health education, knowledge, and experiences are shown in Table 7. More than half of respondents (60\%) reported that a teacher had covered at least one topic related to life skills/family life education in school within the previous school year (2016). The most frequently mentioned topics (multiple responses possible) were: health and hygiene (96\%), HIV/AIDS (94\%), puberty (92\%), abstinence (87\%), selfesteem (74\%), communication (73\%), and pregnancy (65\%). Only one-quarter (26\%) of those who had received life skills/family education had learned about contraceptives or family planning within the previous year. In addition to education provided by teachers, $18 \%$ of girls received similar education from an outside NGO or community-based organization (CBO) provided in school during the 2016 school year. One-third of these students received the education once or twice per month (35\%), 36\% received it less often, and $29 \%$ received it more often.

A reproductive health knowledge score was created from 20 items assessing knowledge regarding puberty, menstruation, pregnancy, vaginal infections, early marriage, reproductive health rights, and HIV/AIDS. The mean score was 10.6 out of 20, with girls in Ganze scoring significantly higher (11.1) as compared to girls from Kaloleni (10.5) and Magarini (10.1). About half of girls (50\% Ganze; 46\% Kaloleni; 49\% Magarini) knew that there is a fertile period during the menstruation cycle when a woman is more likely to become pregnant if she has sexual intercourse. Of those, only $10 \%$ correctly identified this time as halfway between two periods. The majority of girls (91\%) had heard of at least one method of family planning. Only half of girls (51\%) could spontaneously mention a modern method of contraception without being prompted (i.e., pills, IUDs, injectables, implants, male condoms, female condoms, and emergency contraception), and, on average, respondents spontaneously named two of the six modern methods. Thirteen percent of girls spontaneously mentioned condoms as a contraceptive method, and an additional $62 \%$ had heard of condoms when asked about them directly. Therefore, a quarter of girls (25\%) had never heard of the male condom, and this proportion was significantly higher in Magarini (29\%) as compared to Ganze (22\%) and Kaloleni (26\%).

All girls were asked whether they had experienced symptoms of vaginal infections (bad smelling abnormal genital discharge), symptoms of urinary tract infections (i.e., pain while urinating, together with a frequent need to urinate), and genital sores or genital ulcers within the previous 12 months. Twenty-one percent of girls reported experiencing symptoms of vaginal infections and urinary tract infections, while $13 \%$ reported experiencing symptoms of genital sores or ulcers. Among those that reported any of the above, only one-fifth (20\%) sought treatment for these symptoms.

TABLE 7 Reproductive health education, knowledge, and experiences, Nia baseline sample, Kilifi County

\begin{tabular}{|c|c|c|c|c|c|}
\hline & \multicolumn{4}{|c|}{ Subcounty } & \multirow[b]{2}{*}{$P$ Value } \\
\hline & $\begin{array}{c}\text { Ganze } \\
(\mathrm{N}=1,149) \\
\%\end{array}$ & $\begin{array}{c}\text { Kaloleni } \\
(\mathrm{N}=1,247) \\
\%\end{array}$ & $\begin{array}{c}\text { Magarini } \\
(\mathrm{N}=1,093) \\
\%\end{array}$ & $\begin{array}{c}\text { Total } \\
(\mathrm{N}=3,489) \\
\%\end{array}$ & \\
\hline $\begin{array}{l}\text { Percent that received any life skills/family life } \\
\text { education from teacher in } 2016 \text { school year }\end{array}$ & $60.8 \%$ & $61.4 \%$ & $56.7 \%$ & $59.7 \%$ & 0.049 \\
\hline $\begin{array}{l}\text { Reproductive Health Knowledge Test Score [mean } \\
\text { (SD)] }\end{array}$ & $11.1(3.0)$ & $10.5(3.1)$ & $10.1(3.2)$ & $10.6(3.1)$ & 0.000 \\
\hline$[\min =1 ; \max =20]$ & & & & & \\
\hline $\begin{array}{l}\text { Percent that know there is a fertile period during } \\
\text { the menstruation cycle }\end{array}$ & $50.1 \%$ & $45.8 \%$ & $48.8 \%$ & $48.2 \%$ & 0.000 \\
\hline $\begin{array}{l}\text { Percent that have heard of a family planning } \\
\text { method }\end{array}$ & $92.6 \%$ & $89.2 \%$ & $90.0 \%$ & $90.6 \%$ & 0.012 \\
\hline $\begin{array}{l}\text { Percent that spontaneously mention a modern } \\
\text { method of contraceptiona } \\
\text { Percent that know of the male condom }\end{array}$ & $52.9 \%$ & $50.0 \%$ & $50.0 \%$ & $51.0 \%$ & 0.269 \\
\hline Spontaneously mention & $16.4 \%$ & $13.5 \%$ & $8.5 \%$ & $12.9 \%$ & 0.000 \\
\hline Recognize & $62.1 \%$ & $60.8 \%$ & $63.0 \%$ & $61.9 \%$ & \\
\hline No & $21.5 \%$ & $25.7 \%$ & $28.6 \%$ & $25.2 \%$ & \\
\hline $\begin{array}{l}\text { Experienced vaginal infection in previous } 12 \\
\text { months (i.e., bad smelling abnormal genital } \\
\text { discharge) }\end{array}$ & $21.9 \%$ & $20.5 \%$ & $18.9 \%$ & $20.5 \%$ & 0.000 \\
\hline $\begin{array}{l}\text { Experienced urinary tract infection in previous } 12 \\
\text { months (i.e., pain when urinating, together with } \\
\text { frequent need to urinate) }\end{array}$ & $22.3 \%$ & $19.3 \%$ & $22.5 \%$ & $21.3 \%$ & 0.000 \\
\hline $\begin{array}{l}\text { Experienced a genital sore or genital ulcer in } \\
\text { previous } 12 \text { months }\end{array}$ & $11.1 \%$ & $13.6 \%$ & $13.0 \%$ & $12.6 \%$ & 0.000 \\
\hline
\end{tabular}

a Modern methods include: pills, IUDs, injectables, implants, male condoms, female condoms, and emergency contraception. 


\section{Marriage, Sexual Behavior, and Contraception}

Table 8 presents data on marriage, sexual behavior, and contraception. Although the ACASI method was used to collect data on marriage and sexual behavior, self-report data on sexual activity may be subject to measurement error. Only six girls had ever been married, while 35 had previously lived with a boyfriend. About one-tenth of respondents (10\% Ganze; 13\% Kaloleni; 15\% Magarini) reported ever having had sex; Magarini had a significantly higher proportion of sexually experienced girls. Older girls, between the ages of 15 and 22, were significantly more likely to report sex (13\% Ganze; 16\% Kaloleni; 20\% Magarini) as compared to younger girls ages 10 to 14 (6\% Ganze; 7\% Kaloleni; 9\% Magarini). Of the sexually experienced girls, only 8 had ever given birth. The mean age at first sex for those reporting sexual activity was 11.7 years, and the median age was 13 years. Most sexually experienced girls reported their first sexual partner as their boyfriend (47\%), followed by a male friend (21\%) or a casual acquaintance (10\%). About $19 \%$ of girls did not know the age of the first sexual partner, $60 \%$ stated that he was about the same age, $12 \%$ reported that he was younger, and $9 \%$ reported that he was older. When asked whether they wanted their first sexual encounter, half of sexually experienced respondents (52\%) reported that they did not want to have sex at the time, $41 \%$ were unsure, and only $8 \%$ wanted to have sex at the time. Approximately one-quarter of girls reported using a condom during their first sexual encounter, with a significantly higher proportion in Ganze and a lower proportion in Kaloleni (15\%) as compared to Magarini (27\%).

Use of contraceptives for prevention of pregnancy or sexually transmitted infections was generally low within this population. Among sexually experienced girls, only one-fifth had ever used a modern contraceptive (32\% Ganze; 15\% Kaloleni; 19\% Magarini), and only 17\% (21\% Ganze; 16\% Kaloleni; 15\% Magarini) were currently using any family planning method to delay or avoid getting pregnant. Rates of contraceptive use were significantly higher in Ganze compared to the other two subcounties. The most common methods that girls were currently using (multiple responses possible) were: condoms (77\%), withdrawal (18\%), rhythm method (11\%), injectables (8\%), pills (5\%), and emergency contraceptives (4\%). Of those who were not currently using any method, about $73 \%$ knew a place where they could obtain a method of family planning. All sexually experienced girls were asked about their perceived ability to go to a place where they could obtain family planning and they responded as follows: easy $(18 \%)$, difficult (32\%), not possible (24\%), and don't know (26\%). Consistent condom use was low among sexually experienced girls, with most reporting that they never $(62 \%)$ or sometimes $(22 \%)$ use a condom every time they have sex, and only $16 \%$ indicating that they always do so.

About $18 \%$ of sexually experienced girls reported having engaged in transactional sex within the previous six months, including exchanging sex for food, shelter, school fees, beauty products, and other things. At least a tenth of sexually experienced girls in Ganze (11\%) and in Magarini (12\%) had engaged in sex for sanitary pads in the previous six months, compared to $5 \%$ of girls in Kaloleni. It should be noted that these girls represent a small proportion of the entire sample. 


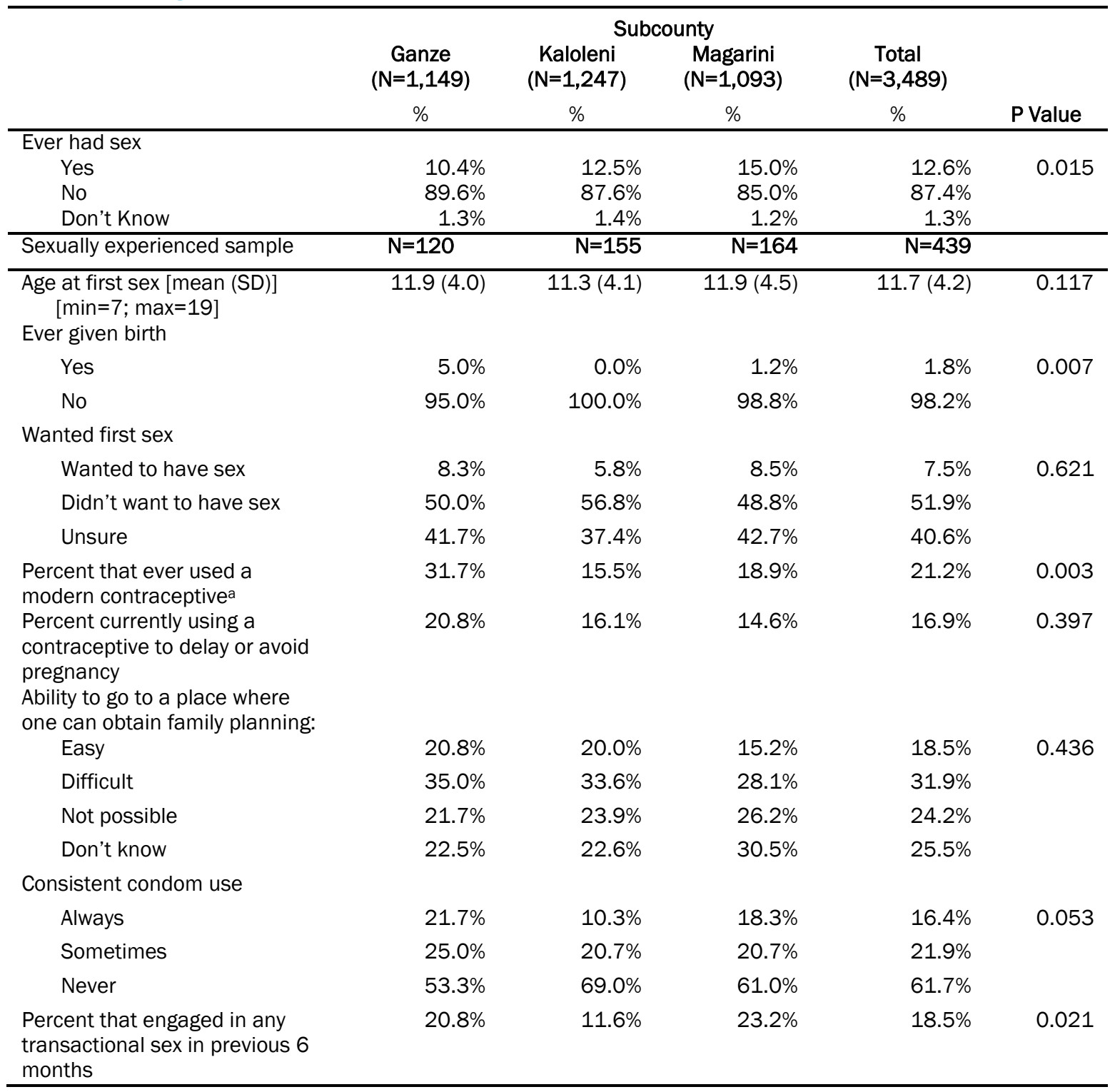

a Modern methods include: pills, IUDs, injectables, implants, male condoms, female condoms, and emergency contraception. 


\section{Key Findings and Implications}

The data presented from the baseline survey provide a multidimensioned description of the girls who will be participating in the Nia Project and the schools they attend. Overall, the schools in the sample exhibit a considerable range in quality from very poor to relatively high. Analyses at endline will determine whether poor school quality serves as a barrier to program impact. Traditionally, girls entering Class 7 are around 12 or 13 years old-just at the start of puberty and adolescence. In reality, a substantial proportion of the girls are already aged 15 and above, partly due to class repetition, indicating a greater likelihood of sexual experiences and a need for sexual and reproductive health (SRH) information.

Girls reported high educational aspirations, although some did not expect to complete secondary school due inability to pay school fees. Despite parents' low educational levels, parents generally approved of girls' continued schooling. High levels of school engagement were reported, with most girls believing that they are comfortable participating in class and capable of doing well in school.

Although girls have some access to disposable sanitary pads, there is still a significant need for products to manage menstruation demonstrated by the large proportion of the girls who report that they do not have enough pads, and those who did not receive pads in school in the previous term. This finding signals gaps in the government distribution program that can be filled by a program such as the Nia Project. In addition, girls shared feelings of shame and discomfort regarding their period that can potentially be improved through intervention sessions and discussions providing information on menstruation. A very small percent of girls reported missing school due to menstruation. School attendance data will be collected from both girls and boys over the course of the intervention to determine whether there are gender differences in absenteeism. The data will also be used to document the mean number of days actually missed by girls in control arms as compared to those receiving Nia pads.

Relatively low scores on the self-efficacy and decision-making scales, together with inequitable gender norms and a high justification of intimate-partner violence, suggest that there is substantial room for improvement to positively affect the girls in these domains. Similarly, the limited SRH knowledge, despite some exposure to life skills/family health education in schools, points to the value of a more comprehensive curriculum focusing on these issues. In addition, the girls who have already initiated sex report inconsistent condom use and very low use of other contraceptive methods, putting them at high risk of pregnancy and sexually transmitted infections (STIs), and increasing the likelihood that they will stop their education. As those girls are likely to continue sexual activity, and others are likely to initiate sex in the next two years, a need for programming exists to increase their selfefficacy on how to prevent exposure to STIs and unwanted pregnancies. The low rates of wanted first sex and selfreporting of transactional sex by a portion of girls indicates a need for content in the curriculum dealing with issues related to gender and power in relationships.

Overall, the baseline findings describe a cohort of school-going adolescent girls with high educational aspirations, but who have a gap in social and personal competencies to aid in completion of secondary education and even continue to tertiary education. The Nia Project has the potential to bridge that gap and is poised as one of the first rigorous, randomized controlled trials to explore the role of sanitary pad distribution and reproductive health education-individually and in combination-to improve girls' educational and SRH outcomes. The findings of this study will make a critical contribution to filling an evidence gap in the field of MHM and, in so doing, will guide education and health policy in this area in Kenya and in the region. 


\section{References}

Behague, S., K. Christenson, S. Martin, M. Wysong, and K. Kibusu. 2006. Tuko Pamoja: Adolescent Reproductive Health and Life Skills Curriculum. Nairobi, Kenya: Program for Appropriate Technology in Health (PATH).

Crichton, J., L. Ibisomi, and S.O. Gyimah. 2012. "Mother-daughter communication about sexual maturation, abstinence and unintended pregnancy: Experiences from an informal settlement in Nairobi, Kenya," Journal of Adolescence 35(1): 21-30.

Crofts, T. and J. Fisher. 2012. "Menstrual hygiene in Ugandan schools: An investigation of low-cost sanitary pads," Journal of Water Sanitation and Hygiene for Development 2(1): 50-58.

Dolan, C.S., C.R. Ryus, S. Dopson, P. Montgomery, and L. Scott. 2014. "A blind spot in girls' education: Menarche and its webs of exclusion in Ghana," Journal of International Development 26(5): 643-657.

Ecker, N., D. Kirby, and P. Gordon. 2009. International Technical Guidance on Sexuality Education: An Evidence-Informed Approach for Schools, Teachers, and Health Educators. Paris: UNESCO.

Haberland, N. and D. Rogow. 2015. "Sexuality education: Emerging trends in evidence and practice," Journal of Adolescent Health 56(1): S15-S21.

Haberland, N.A. 2015. "The case for addressing gender and power in sexuality and HIV education: A comprehensive review of evaluation studies," International Perspectives on Sexual and Reproductive Health 41(1): 31-42.

Hennegan, J. and P. Montgomery. 2016. "Do menstrual hygiene management interventions improve education and psychosocial outcomes for women and girls in low and middle income countries? A systematic review," PloS One 11(2): e0146985.

Kenya National Bureau of Statistics and ICF International. 2015. Kenya Demographic and Health Survey 2014. Calverton, Maryland.

Lloyd, C.B. 2013. Education for Girls: Alternative Pathways to Girls' Empowerment. Paper commissioned by Girl Hub, a strategic partnership between Nike Foundation and the UK Department for International Development.

Mason, L., E. Nyothach, K. Alexander, et al. 2013. "'We keep it secret so no one should know'-A qualitative study to explore young schoolgirls attitudes and experiences with menstruation in rural Western Kenya," PloS One 8(11): e79132.

McMahon, S.A., P.J. Winch, B.A. Caruso, et al. 2011."'The girl with her period is the one to hang her head': Reflections on menstrual management among schoolgirls in rural Kenya," BMC International Health and Human Rights 11(1): 7.

Ministry of Education, Science and Technology. 2012. A Policy Framework for Education: Aligning Education and Training to the Constitution of Kenya (2010) and Kenya Vision 2030 and Beyond. Retrieved from Nairobi, Kenya: https://kemi.ac.ke/index.php/downloads/category/2-kemi-library?download=4:policy-framework-for-education$\underline{2012}$

Ministry of Education, Science and Technology. 2014. Basic Education Statistical Booklet. Retrieved from Nairobi, Kenya: https://www.kicd.ac.ke/images/ICT/2014BasicEducationStatisticalBooklet.pdf

Montgomery, P., C.R. Ryus, C.S. Dolan, S. Dopson, and L.M. Scott. 2012. "Sanitary pad interventions for girls' education in Ghana: A pilot study," PloS One 7(10): e48274.

Mukuru, E. 2008. Final report on the impact of feminine hygiene on girls participation in education in Kenya. Retrieved from Nairobi, Kenya.

Population Council. 2012. Sexuality Education: A Ten-Country Review of School Curricula in East and Southern Africa. Retrieved from Paris.

Schwarzer, R. and M. Jerusalem. 2010. "The general self-efficacy scale (GSE)," Anxiety, Stress, and Coping 12: 329345.

Sommer, M. 2009. "Ideologies of sexuality, menstruation and risk: Girls' experiences of puberty and schooling in northern Tanzania," Culture, Health \& Sexuality 11(4): 383-398.

Sommer, M. 2010. "Where the education system and women's bodies collide: The social and health impact of girls' experiences of menstruation and schooling in Tanzania," Journal of Adolescence 33(4): 521-529.

Sommer, M. 2011. "An overlooked priority: Puberty in sub-Saharan Africa," American Journal of Public Health, 101(6): 979-981.

Sumpter, C. and B. Torondel. 2013. "A systematic review of the health and social effects of menstrual hygiene management," PloS One 8(4): e62004.

Tegegne, T.K. and M.M. Sisay. 2014. "Menstrual hygiene management and school absenteeism among female adolescent students in Northeast Ethiopia," BMC Public Health 14(1): 1.

Wilson, E., J. Reeve, and A. Pitt. 2014. "Education. Period. Developing an acceptable and replicable menstrual hygiene intervention," Development in Practice 24(1): 63-80.

Wilson, E., J. Reeve, A. Pitt, B. Sully, and S. Julious. 2012. INSPIRES: Investigating a reusable sanitary pad intervention in a rural educational setting-evaluating the acceptability and short term effect of teaching Kenyan school girls to make reusable sanitary towels on absenteeism and other daily activities: A partial preference parallel group, cluster randomised control trial.

ZanaAfrica. 2017. Nia Yetu Reproductive Health and Life Skills Manual for Young Adolescent Girls. Nairobi, Kenya: ZanaAfrica Group. 


\section{Acknowledgments}

We would like to thank the Bill \& Melinda Gates Foundation for investing in this research study. We thank ZanaAfrica for providing leadership for the project implementation, including coordinating stakeholders and developing the intervention materials-Nia Teen sanitary pads, Nia Teen magazine, and the Nia Yetu curriculum. We acknowledge the efforts of others who contributed to the development of the study design and the research instruments, including Barbara Mensch and Stephanie Psaki, Population Council co-investigators; Annie Smith, formerly of ZanaAfrica; ZanaAfrica staff members; and members of the Nia Project Research Advisory Committee (RAC)-Caroline Kabiru, Cynthia Lloyd, and Matthew Freeman. We are grateful for the support received by Kilifi County government officials and stakeholders who participated in randomization meetings, particularly Kilifi County Department of Education, Ministry of Education, Science and Technology, the County Department of Health, and the Ministry of Interior and Coordination of the National Government. Finally, we are indebted to the young girls from Kilifi who shared with us their invaluable insights, experiences, and opinions. 
Nairobi, Kenya

popcouncil.org

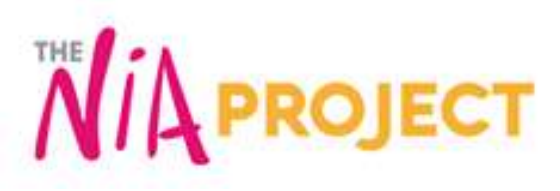

POPULATION
COUNCIL
Ideas. Evidence. Impact. 